\title{
Isolation and Characterization of Nitrogen-deregulated Mutants of Streptomyces clavuligerus
}

\author{
By VICTORIA BASCARÁN, CARLOS HARDISSON AND \\ ALFREDO F. BRA NA* \\ Laboratorio de Microbiología, Departamento de Biologia Funcional, Facultad de Medicina, \\ Universidad de Oviedo, 33006 Oviedo, Spain
}

(Received 9 February 1989; revised 26 April 1989; accepted 17 May 1989)

Two screening methods for isolation of mutants of Streptomyces clavuligerus with altered control of nitrogen metabolism enzymes are described. Thirty-eight prototrophic mutants with simultaneous deregulation of urease and glutamine synthetase were isolated. Nine mutants were examined in more detail and they also showed deregulated formation of arginase and ornithine aminotransferase. Different patterns of altered control of all four enzymes were observed. Inactivation of glutamine synthetase after ammonium shock took place to different extents in these nine strains, and seven of them had a thermosensitive glutamine synthetase activity. It is concluded that a system of nitrogen control, in which glutamine synthetase has a key role, is present in $S$. clavuligerus. Cephalosporin production was depressed by ammonium in all the mutants, irrespective of the alterations in nitrogen control of primary metabolism.

\section{INTRODUCTION}

In some micro-organisms, a variety of metabolic pathways involved in nitrogen assimilation are regulated in response to nitrogen availability. Processes such as ammonium assimilation, transport and catabolism of nitrogen compounds, and nitrogen fixation are usually subject to this type of control. In general terms, under conditions of nitrogen excess the cells utilize ammonium preferentially and repress the mechanisms of utilization of alternative nitrogen sources. When nitrogen becomes limiting these alternative routes can be activated (Magasanik, 1982; Merrick, 1988).

Such a system of nitrogen regulation has been studied in detail only in enteric bacteria (the $n t r$ system). It constitutes a complex regulon with its own sigma factor and a series of proteins able to recognize the nitrogen status of the cell and to act accordingly on the expression of genes under nitrogen control (Magasanik, 1982; Merrick, 1988). Other Gram-negative bacteria such as representatives of Pseudomonas (Dixon, 1986; Janssen et al., 1982), Thiobacillus (Barros et al., 1985), Azotobacter (Toukdarian \& Kennedy, 1986), and members of the Rhizobiaceae (Nixon et al., 1986; Ronson et al., 1987; Rossbach et al., 1987; Szeto et al., 1987) appear to have regulatory circuits resembling the $n t r$ system, whereas a different mechanism may operate in other groups (Singh et al., 1985; Tumer et al., 1983). Amongst Gram-positive bacteria, the formation of enzymes involved in ammonium assimilation, especially glutamine synthetase (GS; EC 6.3.1.2), is influenced by the nitrogen source in Bacillus (Schreier et al., 1981, 1985) and Clostridium (Usdin et al., 1986; Janssen et al., 1988), but nitrogen control of enzymes involved in utilization of nitrogen sources has rarely been reported (Baumberg \& Harwood, 1979; Broman et al., 1978; Golden \& Bernlohr, 1985). In any case, evidence for a global regulatory network equivalent to the $n t r$ system is lacking in Gram-positive bacteria (Schreier et al., 1982, 1985).

Abbreviations: GS, glutamine synthetase; OAT, ornithine aminotransferase; SVPDE, snake venom phosphodiesterase. 
We have provided evidence that in the Gram-positive bacterium Streptomyces clavuligerus the formation of at least four enzyme activities is controlled according to the nature of the nitrogen source supplied (Bascarán et al., 1989). These activities, arginase (EC 3.5.3.1), ornithine aminotransferase (OAT; EC 2.6.1.13), urease (EC 3.5.1.5), and GS, decreased in media with ammonium, and the latter two enzymes suffered coordinated changes in mutants altered in the enzymes of ammonium assimilation. The isolation of a high number of deregulated mutants has now provided evidence for a regulatory linkage between these activities, suggesting that a global system of nitrogen control may exist in this species. In addition, we have tested the effect of these mutations on the production of cephalosporins by these strains, a process that is also under nitrogen control (Braña et al., 1985, 1986b).

\section{METHODS}

Micro-organisms, media and enzyme and chemical analysis. S. clavuligerus NRRL 3585 (A TCC 27064) was used as the wild-type strain. Mutant derivatives obtained in the course of this work are described in Results. Media, culture conditions, analytical techniques, and the procedures for enzyme determinations are described in the accompanying paper (Bascarán et al., 1989).

Isolation of deregulated mutants. Spores of wild-type $S$. clavuligerus were mutagenized with $N$-methyl- $N^{\prime}$-nitro- $N$ nitrosoguanidine (Braña et al., 1986a). Two alternative screening methods were then used.

Method 1. The mutagenized spores were plated on MF medium, without MOPS and supplemented with $0 \cdot 2 \%$

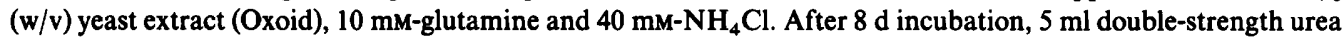
broth (Difco) was poured onto each plate and incubation continued for another $24 \mathrm{~h}$. Under these repressing conditions, wild-type colonies have a urease-negative phenotype, and the colour of the medium remains orange. Mutants deregulated for urease formation would produce ammonia from urea and cause a change in the colour of the $\mathrm{pH}$ indicator, phenol red. Of approximately 3000 colonies screened, one caused a colour change to red and was subsequently purified.

Method 2. The mutagenized spores were plated on sporulation medium supplemented with 5 mM-glutamine, to give approximately 70 colonies per plate. Colonies that had grown after $8 \mathrm{~d}$ were replica-plated to an indicator medium which was based on MF but without MOPS, with $\mathrm{K}_{2} \mathrm{HPO}_{4}$ at $0.35 \mathrm{~g} \mathrm{l}^{-1}$, and supplemented with $0 \cdot 2 \%$ (w/v) yeast extract, $40 \mathrm{~mm}-\mathrm{NH}_{4} \mathrm{Cl}, 0.0025 \%(\mathrm{w} / \mathrm{v})$ phenol red, and $2 \%(\mathrm{w} / \mathrm{v})$ agar, $\mathrm{pH} 6.7$. After autoclaving, $12.5 \mathrm{mM}$-glutamine and $2 \%(\mathrm{w} / \mathrm{v})$ urea (final concentrations), previously sterilized by filtration, were added. Plates were incubated for up to $12 \mathrm{~d}$ at $30^{\circ} \mathrm{C}$ and colonies causing alkalinization of the medium were streaked onto sporulation medium with $5 \mathrm{~mm}$-glutamine and retested in indicator medium. Forty-eight such mutants were isolated in two independent experiments, from about 20000 colonies examined.

Antibiotic assays. Production of cephalosporins, mainly cephamycin C (Braña et al., 1985), was estimated in solid or liquid MF medium. In solid medium the micro-organisms were seeded to give lawns on plates containing

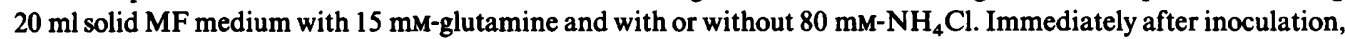
small plugs ( $2.5 \mathrm{~mm}$ in diameter) of inoculated agar were removed using sterile straws. The plugs were incubated at $30^{\circ} \mathrm{C}$ in a humidified atmosphere and their antibiotic content determined after 4 and $7 \mathrm{~d}$. The cultures in liquid medium contained $15 \mathrm{~mm}$-glutamine, with or without $40 \mathrm{mM}-\mathrm{NH}_{4} \mathrm{Cl}$, and were sampled daily. In both cases, the antibiotic produced was measured by bioassay with Escherichia coli ESS as the indicator organism. One unit of antibiotic is defined as the amount producing an inhibition zone equivalent to $1 \mu \mathrm{g}$ cephalosporin $\mathrm{C}$.

\section{RESULTS}

\section{Isolation of mutants}

Method 1 gave a high risk of cross-contamination between colonies and, as became apparent later, a weak colour change. Nevertheless, one strain, designated M1, with altered production of urease (see below), was isolated. This mutant strain was used to develop an improved indicator medium based on the same principle, but with a very low buffering capacity resulting in a more intense response (method 2). Unfortunately, plating of the mutagenized spores directly on this indicator medium gave a lower number of colonies than expected, presumably due to some toxic effect of phenol red on spore germination. Therefore, an intermediate step of growth on sporulation medium was added, and the resulting colonies were replicated to indicator medium before reaching the sporulation stage. Glutamine was included in media throughout the selection procedure to ensure recovery of mutants exhibiting glutamine auxotrophy, a phenotype frequently found in nitrogen-deregulated mutants of enteric bacteria. Amongst the 
48 mutant strains isolated in this way in two independent experiments, there was considerable variation in the extent of the colour change observed.

\section{Characterization of mutants}

None of the strains isolated exhibited a glutamine requirement. The formation of GS and urease was tested in all the strains in MF medium with alanine, alanine plus ammonium, and alanine plus ammonium plus glutamine, conditions that result in a progressive decrease in urease activity in the wild-type. Four of the mutants did not grow in any of these defined media and were not investigated further. In seven of the strains, the activities and regulation of GS and urease were similar to the wild-type. These strains may be revertants or represent false mutant isolations. All the remaining strains (38) were simultaneously altered in the regulation of GS and urease when compared to the wild-type. We selected nine strains that may be considered as representative of the different regulatory patterns observed. The regulation of GS, urease, OAT and arginase was investigated in the wild-type and the nine mutants (Table 1). The most dramatic effects were observed for GS, with activities lower than the wild-type repressed levels in most of the mutants, and for urease, which showed a variety of deregulated behaviours. The formation of OAT and arginase in the different media used was also altered in different ways with respect to the regulation observed in the wild-type. Arginase activities in two of the mutants (M32 and M44) could not be compared due to their lack of growth in liquid MF medium with arginine as the sole nitrogen source. From the results shown in Table 1, it is evident that in many cases the mutations did not affect the control of the four enzymes tested in the same way. Histidase formation, which is not under nitrogen control in $S$. clavuligerus (Bascarán et al., 1989), was also studied in these strains. Both the induced activities (in MF medium with alanine plus histidine) and the basal levels (with alanine) of the mutants were within $\pm 30 \%$ of the respective histidase activities measured in the wild-type (data not shown).

\section{Characteristics of GS of the mutants}

Given the central role of GS and its adenylylation system in the known systems of nitrogen control (Magasanik, 1982; Merrick, 1988), we attempted to investigate in our mutants possible alterations in the mechanism of GS modification in S. clavuligerus (Bascarán et al., 1989). During preliminary attempts to reactivate GS in the mutants by incubation with snake venom phosphodiesterase (SVPDE), it was observed that GS activity decreased dramatically in many cases. The stability of the enzyme was tested by mild heat treatments of crude extracts $\left(45^{\circ} \mathrm{C}\right.$ or $60^{\circ} \mathrm{C}, 15 \mathrm{~min}$ ), that have little or no effect on wild-type GS, followed by assay at $20^{\circ} \mathrm{C}$ instead of $35^{\circ} \mathrm{C}$. As shown in Table 2, these procedures affected, more or less severely, the GS activity of seven of the nine strains tested. As a consequence, the conditions for reactivation of GS were altered in an attempt to find a compromise between the stability of the GS and the activity of the SVPDE: crude extracts were incubated for $1 \mathrm{~h}$ at $20^{\circ} \mathrm{C}$ with a double concentration $(200 \mu \mathrm{g}$ $\mathrm{ml}^{-1}$ ) of SVPDE, and the activities were then assayed at $20^{\circ} \mathrm{C}$ with reaction times usually less than $15 \mathrm{~min}$.

Ammonium shock of cultures growing with glutamate caused a rapid drop in GS activity in all the mutants, indicating that they conserved a functional system of GS modification (Table 2). However, the degree of inactivation was lower in most of the mutants than in the wild-type, with a considerable variation between strains. The subsequent treatment of the extracts from ammonium-shocked cultures with SVPDE allowed recovery of the GS activities to different extents (except for mutants M16 and M32). Control treatments with water substituting for SVPDE showed partial losses of GS activity after $1 \mathrm{~h}$ at $20^{\circ} \mathrm{C}$ in the extracts from mutants with a thermosensitive GS, which probably explains the inability to recover the original activities in these mutants. The fraction of modified GS during exponential growth was tentatively estimated by incubation of the corresponding extracts with SVPDE (Table 2). GS activity of the wild-type and the mutants M1, M44 and M49 increased to a similar extent (20-30\%). This increase was higher in M3 and M31, while the instability of the enzymes from M16, M32 and M38 prevented any estimation of the modified enzyme. 


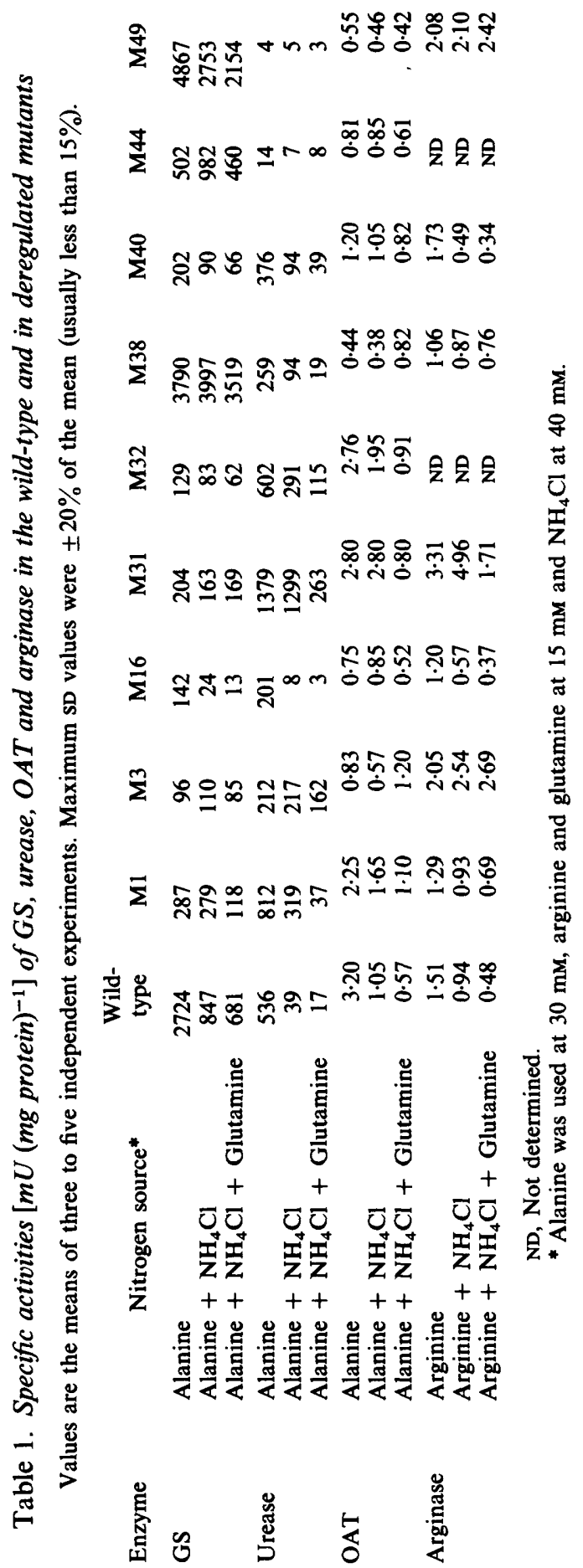


Table 2. Characteristics of GS from the wild-type and from deregulated mutants

Heat treatments were done three times with different extracts. Other values are from duplicate experiments. The results shown are mean values; SD values were less than $\pm 18 \%$ of the mean.

\begin{tabular}{|c|c|c|c|c|c|}
\hline \multirow[b]{3}{*}{ Strain } & \multicolumn{5}{|c|}{ Relative GS specific activity ( $\%)$} \\
\hline & \multicolumn{2}{|c|}{ Heat-treated ${ }^{*}$} & \multirow{2}{*}{$\begin{array}{c}\text { Ammonium } \\
\text { shock } \dagger\end{array}$} & \multirow{2}{*}{$\begin{array}{l}\text { Ammonium } \\
\text { shock } \\
+ \text { SVPDE }\end{array}$} & \multirow[b]{2}{*}{ SVPDE $\S$} \\
\hline & $45^{\circ} \mathrm{C}$ & $60^{\circ} \mathrm{C}$ & & & \\
\hline Wild-type & 101 & 86 & 17 & 95 & 122 \\
\hline M1 & 64 & 22 & 38 & 67 & 126 \\
\hline M3 & 32 & 1 & 53 & 80 & 159 \\
\hline M16 & 38 & 14 & 23 & 24 & 30 \\
\hline M31 & 77 & 21 & 63 & 87 & 176 \\
\hline M32 & 7 & 5 & 80 & 53 & 96 \\
\hline M38 & 47 & 40 & 42 & 55 & 75 \\
\hline M40 & 17 & 10 & 60 & 78 & 112 \\
\hline M44 & 92 & 93 & 80 & 92 & 123 \\
\hline M49 & 92 & 85 & 18 & 97 & 129 \\
\hline
\end{tabular}

* Crude extracts from cells grown in MF medium with glutamate were incubated at $45^{\circ} \mathrm{C}$ or $60^{\circ} \mathrm{C}$ for $15 \mathrm{~min}$. Values given are the percentage of remaining activity after the treatment.

$\dagger$ The activities were measured in extracts of cells grown in MF medium with glutamate and shocked with $20 \mathrm{mM}-\mathrm{NH}_{4} \mathrm{Cl}$ for $30 \mathrm{~min}$. They are expressed as the percentage of the activity measured in extracts of unshocked cells.

‡ Extracts from ammonium-shocked cells were incubated with SVPDE $\left(200 \mu \mathrm{g} \mathrm{ml}^{-1}\right)$ at $20^{\circ} \mathrm{C}$ for $1 \mathrm{~h}$. Values given are relative to those obtained in extracts of unshocked cells.

$\$$ Measured in crude extracts of cells growing with glutamate plus $\mathrm{NH}_{4} \mathrm{Cl}$. The values represent the relative activity after treatment with SVPDE (as in the preceding column) with respect to untreated extracts.

Table 3. Intracellular pool of glutamine in the wild-type and in mutant strain MI

Values are the means of two independent experiments. The maximum deviation from the mean was $\pm 10 \%$.

\begin{tabular}{lcc} 
Nitrogen source* & $3 \cdot 4$ & Strain M1 \\
\cline { 2 - 3 } Wild-type & $3 \cdot 4$ \\
Alanine & $15 \cdot 7$ & $4 \cdot 2$ \\
Alanine $+\mathrm{NH}_{4} \mathrm{Cl}$ & 26.9 & $7 \cdot 4$
\end{tabular}

* Alanine was used at $30 \mathrm{mM}$, glutamine at $15 \mathrm{mM}$, and $\mathrm{NH}_{4} \mathrm{Cl}$ at $40 \mathrm{mM}$.

\section{Other characteristics of the mutants}

The ability of the nine selected mutants to utilize different nitrogen sources was tested in solid MF medium with one of the following added to a final concentration of $10 \mathrm{~mm}$ : alanine, arginine, aspartate, asparagine, glutamate, glutamine, $\mathrm{NH}_{4} \mathrm{Cl}$, proline, serine, threonine or urea. After $7 \mathrm{~d}$ of incubation, growth was observed in all cases, except for strains M3 and M49 in media with serine or threonine. However, marked differences in growth rate and colony size were evident between the strains. In general, the mutants grew poorly, as compared to the wildtype, in media with arginine, $\mathrm{NH}_{4} \mathrm{Cl}$ or urea. Assimilation of ammonium or nitrogen sources that are deaminated is likely to be hampered in most of the mutants due to their low GS activities. This was confirmed with strain $\mathrm{M} 1$, which showed a generation time of $32 \mathrm{~h}$ in liquid MF medium with $\mathrm{NH}_{4} \mathrm{Cl}$ as nitrogen source, against $14 \mathrm{~h}$ for the wild-type under the same conditions. Furthermore, the intracellular pool of glutamine (the immediate product of ammonium assimilation) in media with ammonium or glutamine plus ammonium was much lower in M1 than in the wild-type (Table 3). It was also observed that strain M44 suffered a 
Table 4. Cephalosporin production by the wild-type and by nitrogen-deregulated mutants in MF medium with glutamine or glutamine plus ammonium

Results are the means of two independent experiments. SD values were less than $\pm 17 \%$ of the mean.

\begin{tabular}{lcc} 
Strain & \multicolumn{2}{c}{ Cephalosporins $\left(\mathrm{U} \mathrm{ml}^{-1}\right)^{*}$} \\
\cline { 2 - 3 } Wild-type & Glutamine & Glutamine $+\mathrm{NH}_{4} \mathrm{Cl}+$ \\
M1 & 26.4 & 8.8 \\
M3 & 42.0 & 11.6 \\
M16 & 7.6 & 3.0 \\
M31 & 23.2 & 13.2 \\
M32 & 28.5 & 10.8 \\
M38 & 28.5 & 13.2 \\
M40 & 16.0 & 7.6 \\
M44 & 40.0 & 15.2 \\
M49 & 35.2 & 5.8 \\
& 13.2 & 4.7
\end{tabular}

* Maximum titres achieved throughout the fermentation.

† Glutamine was used at $15 \mathrm{~mm}$ and $\mathrm{NH}_{4} \mathrm{Cl}$ at $40 \mathrm{~mm}$.

partial growth inhibition in the presence of ammonium in the liquid media employed for enzyme determinations.

All the confirmed 38 mutants retained the ability to differentiate and to form spores. Among the nine characterized strains, M3 sporulated poorly whereas the rest did so faster and more heavily than the wild-type. Antibiotic production, measured in plugs of solid medium, was strongly decreased by ammonium in all the mutants. This result was confirmed in the nine selected mutants growing in liquid media. All of them produced cephalosporins, but ammonium lowered the antibiotic titres (Table 4). It seems that ammonium repression of antibiotic production is mediated by mechanisms different from those governing ammonium assimilation (Braña et al., 1986b) or nitrogen control of primary metabolism.

\section{DISCUSSION}

Two methods that allow easy recognition of nitrogen deregulated mutants have been developed. They were inspired by a published method to identify nitrogenase-derepressed mutants of Anabaena variabilis that excreted ammonia (Spiller et al., 1986). In this case, mutants able to produce urease under conditions that are repressing for the wild-type were expected. Although this was true for some of the strains obtained, we were surprised by the isolation of mutants with urease activities even lower than those of the wild-type. In some cases, such as mutant M16, this might be explained by their reduced ability to assimilate ammonium generated in diverse metabolic processes, due to low GS activity. In fact, a glutamine auxotroph strain of $S$. clavuligerus $(g \ln -4)$ produces a weak red colour in indicator medium in spite of its inability to derepress urease (Bascarán et al., 1989). We have no explanation for the isolation of strains like M49 with high GS and repressed urease activities. In any case, method 2 in particular has proved to work efficiently in isolating deregulated strains of $S$. clavuligerus and it might be useful for similar purposes in other species with a nitrogen-controlled urease.

The simultaneous deregulation observed in the formation of four enzymes related to nitrogen nutrition in most of the nine mutants characterized cannot be reasonably attributed to different combinations of multiple mutations and, therefore, it appears that a regulatory linkage exists between all of them. The unaltered formation of histidase suggests that the effects of the mutations are specific for nitrogen-controlled enzymes, although non-specific effects as a consequence of the alterations in nitrogen assimilation cannot be excluded. It is also evident that the mutations do not affect the four activities in the same way (for example, strain M49 has derepressed GS and arginase whereas urease and OAT are maintained at basal levels), which 
indicates regulatory peculiarities. Arginase, at least, is also derepressed by nutrient starvation (V. Bascarán and others, unpublished results), which suggests that multiple promoters and overlapping control mechanisms may be involved in the regulatory diversity. GS was severely affected in all the mutant strains isolated, most of which had very low activities. Seven of the nine mutants characterized had a thermosensitive GS enzyme, which implies that the activities measured may underestimate the amount of GS protein produced and, more importantly, that the mutations probably lie in the GS structural gene $(g \ln A)$. There are at least three possibilities to explain the relationship between these abnormal GS enzymes and the deregulated formation of nitrogen catabolic enzymes. First, assuming that the intracellular glutamine levels act as a signal of nitrogen abundance, as occurs in other bacteria (Magasanik, 1988), ammonium repression may be alleviated if glutamine synthesis is decreased in strains with very low GS activity. In this case addition of glutamine should restore, totally or partially, nitrogen repression. This is exemplified by the results obtained with strain M1. Another possibility is the existence of regulatory genes closely linked to $g \ln A$, as occurs in the $n t r$ system (Magasanik, 1982). Mutations in $g \ln A$ might then have polar effects on the expression of these hypothetical adjacent genes. Finally, in Gram-positive spore-forming bacteria, although there is no evidence for a global system of nitrogen control, GS appears to regulate its own synthesis in response to the supply of nitrogen source. Different mutations or deletions in $g \ln A$ lead to deregulated GS synthesis (Dean et al., 1977; Schreier \& Sonenshein, 1986; Janssen et al., 1988). The high frequency of $S$. clavuligerus deregulated mutants with an apparently altered GS polypeptide suggests that GS protein might have a similar role, not only in controlling its own synthesis, but also in the formation of some nitrogen catabolic enzymes. Of course, none of the above possibilities are mutually excluding and different mechanisms, or a combination of them, may be involved in the generation of the diverse phenotypes.

The mechanism of GS modification by adenylylation has a key role in nitrogen control in enteric bacteria, and mutations affecting this process have strong pleiotropic effects (Magasanik, 1982, 1988). All the $S$. clavuligerus mutants characterized were able to modify GS upon ammonium shock. The resulting drop in activity was usually lower than that observed in the wild-type, especially in mutants M32 and M44. This may be due to a deficient modification system, to the reduced glutamine-synthesizing ability of the mutants, to differences in GS protein that result in a different sensitivity to modification, or to the presence of an already partially modified GS. The last possibility was tested in exponential-phase cultures growing with ammonium. Although at least two mutants appeared to have a higher degree of modification, the multiple alternative explanations, complicated by the lability of the enzyme, do not allow us to establish any firm conclusion on the possible role of GS modification in nitrogen control.

In conclusion, $S$. clavuligerus seems to have a regulatory system that participates in the control of several enzymes of nitrogen metabolism, and GS appears to have an important role in this mechanism. The discovery of such a system of control in a Gram-positive bacterium, and its elucidation and manipulation, providing it is widespread within Streptomyces species, should find applications in the industrial use of these micro-organisms.

V. Bascarán is a recipient of a grant from the Plan de Formación de Personal Investigador of the Ministry of Education of Spain.

\section{REFERENCES}

Barros, M. E. C., Rawlings, D. E. \& Woods, D. R. (1985). Cloning and expression of the Thiobacillus ferrooxidans glutamine synthetase gene in Escherichia coli. Journal of Bacteriology 164, 1386-1389.

Bascarán, V., Hardisson, C. \& Braña, A. F. (1989). Regulation of nitrogen catabolic enzymes in Streptomyces clavuligerus. Journal of General Microbiology 135, 2465-2474.
Baumberg, S. \& HaRwood, C. R. (1979). Carbon and nitrogen repression of arginine catabolic enzymes in Bacillus subtilis. Journal of Bacteriology 137, 189196.

Braña, A. F., Wolfe, S. \& Demain, A. L. (1985). Ammonium repression of cephalosporin production by Streptomyces clavuligerus. Canadian Journal of Microbiology 31, 736-743. 
Braña, A. F., Paiva, N. \& Demain, A. L. (1986a) Pathways and regulation of ammonium assimilation in Streptomyces clavuligerus. Journal of General Microbiology 132, 1305-1317.

Braña, A. F., Wolfe, S. \& Demain, A. L. (1986b). Relationship between nitrogen assimilation and cephalosporin synthesis in Streptomyces clavuligerus. Archives of Microbiology 146, 46-51.

Broman, K., Lauwers, N., Stalon, V. \& Wiame, J. M. (1978). Oxygen and nitrate in utilization by Bacillus licheniformis of the arginase and arginine deiminase routes of arginine catabolism and other factors affecting their synthesis. Journal of Bacteriology 135, 920-927.

Dean, D. R., Hoch, J. A. \& Aronson, A. I. (1977). Alteration of the Bacillus subtilis glutamine synthetase results in overproduction of the enzyme. Journal of Bacteriology 131, 981-987.

DiXon, R. (1986). The $x y l A B C$ promoter from Pseudomonas putida TOL plasmid is activated by nitrogen regulatory genes in Escherichia coli. Molecular and General Genetics 203, 129-136.

GoldEN, K. J. \& BERNLOHR, R. W. (1985). Nitrogen catabolite repression of the L-asparaginase of Bacillus licheniformis. Journal of Bacteriology 164, 938-940.

Janssen, D. B., Habets, W. J. A., Marugg, T. \& VaN DER DRIFT,C. (1982). Nitrogen control in Pseudomonas aeruginosa: mutants affected in the synthesis of glutamine synthetase, urease, and NADP-dependent glutamate dehydrogenase. Journal of Bacteriology 151, 22-28.

JANSSEN, P. J., JoNES, W. A., JoNES, D. T. \& WoOdS, D. R. (1988). Molecular analysis and regulation of the $g \ln A$ gene of the Gram-positive anaerobe Clostridium acetobutylicum. Journal of Bacteriology 170, 400-408.

MagasanIK, B. (1982). Genetic control of nitrogen assimilation in bacteria. Annual Review of Genetics 16, 135-168.

MAGASANIK, B. (1988). Reversible phosphorylation of an enhancer binding protein regulates the transcription of bacterial nitrogen utilization genes. Trends in Biochemical Sciences 13, 475-479.

MERRICK, M. J. (1988). Regulation of nitrogen assimilation by bacteria. In The Nitrogen and Sulphur Cycles, pp. 331-361. Edited by J. A. Cole \& S. J. Ferguson. Cambridge: Cambridge University Press.

Nixon, B. T., Ronson, C. W. \& Ausubel, F. M. (1986). Two-component regulatory systems responsive to environmental stimuli share strongly conserved domains with the nitrogen assimilation regulatory genes $n t r B$ and $n t r C$. Proceedings of the National Academy of Sciences of the United States of America 83, 7850-7854.

Ronson, C. W., Nixon, B. T., Albright, L. M. \& AUSUBEL, F. M. (1987). Rhizobium meliloti ntrA $(r p o N)$ gene is required for diverse metabolic functions. Journal of Bacteriology 169, 2424-2431.
Rossbach, S., Schell, J. \& de Bruijn, F. J. (1987). The ntrC gene of Agrobacterium tumefaciens C58 controls glutamine synthetase (GSII) activity, growth on nitrate and chromosomal but not Ti-encoded arginine catabolism pathways. Molecular and General Genetics 209, 419-426.

SCHREIER, H. J. \& Sonenshein, A. L. (1986). Altered regulation of the $g \ln A$ gene in glutamine synthetase mutants of Bacillus subtilis. Journal of Bacteriology 167, 35-43.

SChreIER, H. J., SMITH, T. M., Donohue, T. J. \& BERNLOHR, R. W. (1981). Regulation of nitrogen metabolism and sporulation in Bacillus licheniformis. In Sporulation and Germination, pp. 138-141. Edited by H. S. Levison, A. L. Sonenshein \& D. J. Tipper. Washington DC: American Society for Microbiology.

SCHREIER, H. J., SMITH, T. M. \& BeRnLOHR, R. W. (1982). Regulation of nitrogen catabolic enzymes in Bacillus spp. Journal of Bacteriology 151, 971-975.

SCHREIER, H. J., Fisher, S. H. \& Sonenshein, A. L. (1985). Regulation of expression from the $g \ln A$ promoter of Bacillus subtilis requires the $g \ln A$ gene product. Proceedings of the National Academy of Sciences of the United States of America 82, 33753379.

Singh, H. N., RAI, A. N. \& BAGCHI, S. N. (1985). Evidence for a common genetic regulation of glutamine synthetase and nitrate uptake and reductase in the cyanobacterium Anabaena cycadeae. Molecular and General Genetics 198, 367-368.

Spiller, H., Latorre, C., Hassan, M. E. \& ShanMUGAN, K. T. (1986). Isolation and characterization of nitrogenase-derepressed mutant strains of cyanobacterium Anabaena variabilis. Journal of Bacteriology 165, 412-419.

Szeto, W. W., Nixon, B. T., Ronson, C. W. \& AUSUBEL, F. M. (1987). Identification and characterization of the Rhizobium meliloti ntrC gene: $R$. melilot $i$ has separate regulatory pathways for activation of nitrogen fixation genes in free-living and symbiotic cells. Journal of Bacteriology 169, 14231432.

TOUKDARIAN, A. \& KenNEDY, C. (1986). Regulation of nitrogen metabolism in Azotobacter vinelandii: isolation of $n t r$ and $g \ln A$ genes and construction of $n t r$ mutants. EMBO Journal 5, 399-407.

Tumer, N. E., Robinson, S. J. \& Hasselkorn, R. (1983). Different promoters for the Anabaena glutamine synthetase gene during growth using molecular or fixed nitrogen. Nature, London 306, 337-342.

Usdin, K. P., ZAPPE, H., Jones, D. T. \& WoOds, D. R. (1986). Cloning, expression, and purification of glutamine synthetase from Clostridium acetobutylicum. Applied and Environmental Microbiology 52, 413-419. 